\title{
Moisture handling mechanisms in ice rinks
}

\author{
Juris Pomerancevs ${ }^{1, *}$, Jörgen Rogstam², and Agnese Līckrastiņa ${ }^{3}$ \\ ${ }^{1}$ EKA Baltic SIA, Gustava Zemgala gatve 74, LV-1039 Riga, Latvia \\ ${ }^{2}$ Energi \& Kylanalys AB, Prästgårdsgränd 4, 12544 Älvsjö, Sweden \\ ${ }^{3}$ Riga Technical University, Kaḷķu iela 1, LV-1658 Riga, Latvia
}

\begin{abstract}
The paper addresses the moisture handling function in ice rinks. Dehumidification has an important role in ice rinks to avoid structural damages and maintain a sustainable indoor environment. Field measurement analysis in a number of ice rinks in Sweden is performed, showing the indoor climate dependency on the ambient conditions. Indoor temperatures vary between $+5^{\circ} \mathrm{C}$ to $+10^{\circ} \mathrm{C}$ and humidity ratio between 2.5 to $6.0 \mathrm{gH} 2 \mathrm{O} / \mathrm{kg}$ of air. [1] Moisture source evaluation shows that the most critical load is imposed by air leakages, while internal loads such as people can generate peaks but have a short-term nature. Control strategy of the dehumidification equipment has a significant impact on the appropriate humidity level and moreover poor controls can easily lead to a $30 \%$ energy penalty. [2] [3] In ice rinks it is concluded that the acceptable setpoint is in the range of $0^{\circ} \mathrm{C}$ to $2^{\circ} \mathrm{C}$ dewpoint temperature.
\end{abstract}

\section{Introduction}

Ice arenas are a special type of sports facilities where ice is of the central interest, maintained by a refrigeration system. In modern ice rinks there are several requirements to provide a safe and satisfactory experience for the users, and it involves at least five major technical systems to provide that. These systems are:

- Refrigeration

- Space and hot water heating

- Ventilation

- Lighting

- Dehumidification

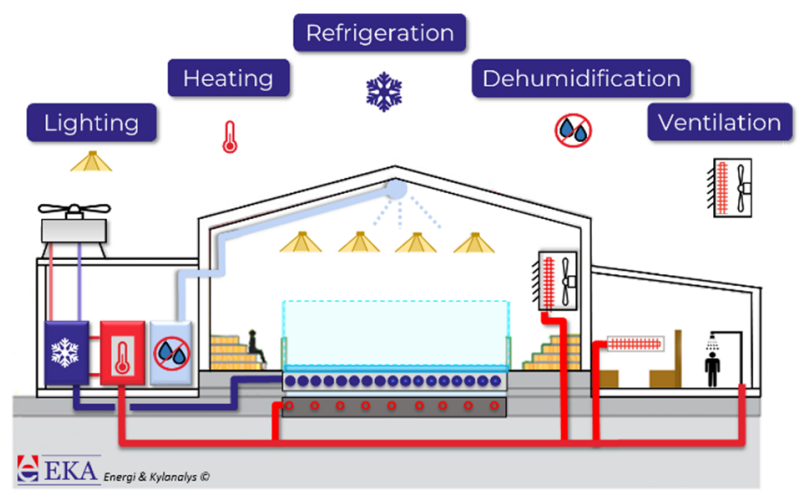

Fig. 1. The "big five" energy systems in a typical ice rink.

The importance of these systems is not only explained by the provided functionality but they also represent more than $90 \%$ of the total energy usage. [4]

This paper focuses on moisture handling in ice rink application with the aim to investigate the importance of dehumidification function. Most of the results are derived from a research project with the name NERIS, which is an abbreviation based on Nordicbuilt: Evaluation and Renovation of Ice halls and Swimming halls - NERIS, the project aim was building a knowledge bank related to moisture handling in ice rinks and swimming halls. The authors $^{1,2}$ took active part in the project which was finished in 2019.

\subsection{Moisture related issues}

A season of an ice rink is typically between August to March, but some arenas run year-round. In modern arenas dehumidification is a must in order to control the quality of the indoor air, keeping it at acceptable level and avoiding problems due to the presence of moisture.

Air moisture mishandling can cause long-term problems such as degradation of structure materials, corrosion of metal, rotting of the wooden structures and development of fungi and bacteria.

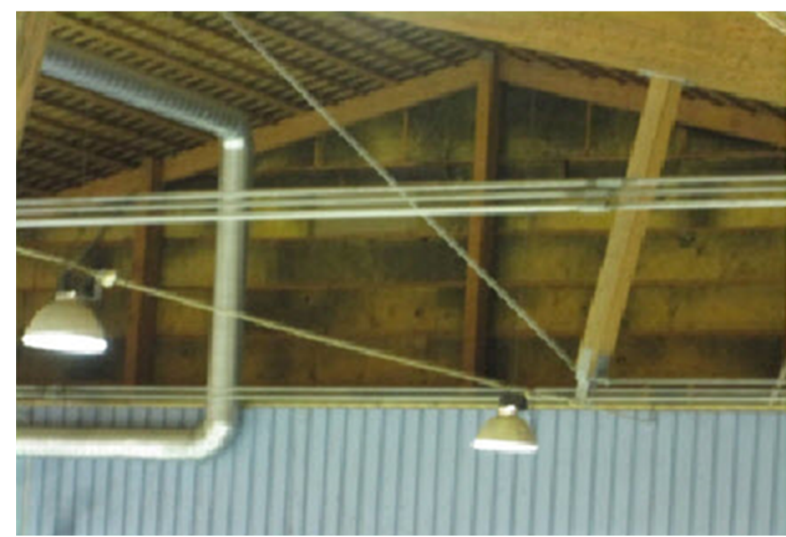

Fig. 2. Mould growth on the ice rink structure.

\footnotetext{
${ }^{*}$ Corresponding author: juris.pomerancevs@ekanalys.se
} 
Arenas are challenged to keep a safe and good sheet of ice when the indoor humidity level or dew point increases to a point that is well above freezing, because the rate at which frost builds up on the ice also increases. To keep the ice from being too soft, operators are forced to run the ice plant at very low temperatures, resulting in the easy build up ruts and heavy snow accumulation from skaters. Typically these periods that require colder ice are the same periods when the outdoor temperatures are elevated; which negatively impacts the ice plant's efficiency and the total hours of operation. [5]

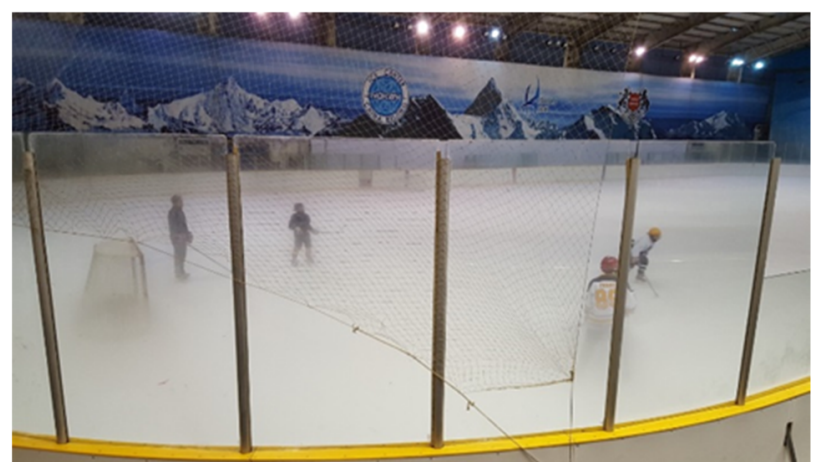

Fig. 3. Fog in an ice rink.

Inadequate moisture removal can lead to dissatisfaction of skaters and spectators because of processes like ice surface softening, drippings from beams, condensation on the protective glass and even fog.

\subsection{Energy usage}

Apart of functional challenges, dehumidification in ice rinks is still a very delicate subject in terms of energy usage concerning these buildings, according to an extensive statistical investigation dehumidification represents about $6 \%$ of the total energy in a typical ice rink. [4]

Dehumidification energy usage data per season in several ice rinks is plotted in Fig. 4. The variations that can be observed between the ice rinks may be dependent on factors such as the moisture load, the control strategy or the season length. By only analyzing this plot it is not possible to conclude what is the influence of each factor. However, these ice rinks are of similar size and made for similar purpose, with insulation, which indicates that the before-mentioned factors can significantly affect the energy-efficiency of an ice rink since the total dehumidification energy usage ranges between 55 to 158 MWh.

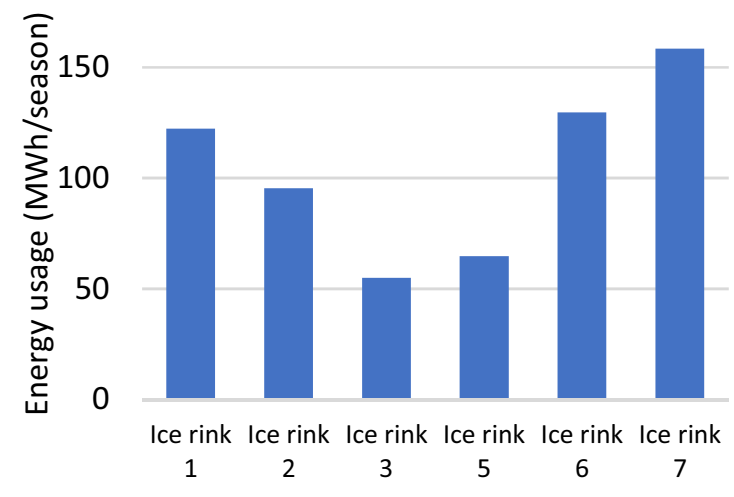

Fig. 4. Dehumidification system energy usage in 7 ice rinks.

\section{Indoor climate Field measurements}

An important part of the project was analysis of the field measurements. Available indoor climate data from 8 ice rinks near Stockholm was used for the season 2015/16 (around 8 months). Resolution of the data is 5 minutes, therefore the results include the dynamic effects. The sensors are permanent and measure temperature as well as relative humidity and are placed by the wall at about $2 \mathrm{~m}$ height. [1]

\subsection{Indoor temperature}

Fig. 5 shows the indoor temperature profiles averaged for a month. In the beginning of the season it is normal that the temperature level is up to $12^{\circ} \mathrm{C}$, which obviously leads to high thermal load at the start-up. Once the refrigeration system has started to cool the rink floor, the temperature drops in the arena room. There is, however, a considerable thermal mass to work with when rink floor, building, etc. are at "summer temperatures". Most smaller ice halls, where the climate is controlled, keep controlled air temperatures in the range of 5 to $10^{\circ} \mathrm{C}$ during normal operation. In some cases where the ice halls are uninsulated, the temperature in winter can drop significantly.

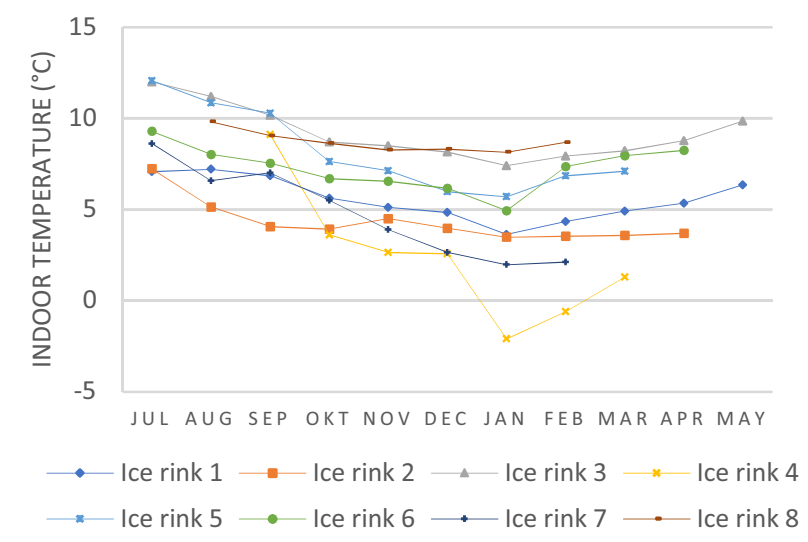

Fig. 5. Monthly average indoor air temperature.

The indoor temperature trend is similar for all ice rinks studied. It is only in ice rink 4, where the temperature 
drops much more during the cold period, which is due to an uninsulated building. Interestingly enough, this is the warmest ice rink in the beginning of the season and among the coldest in the end, which illustrates challenges with uninsulated ice rinks without climate control, i.e. influence of the ambient climate is much more significant.

\subsection{Relative humidity}

In Fig. 6 the monthly average relative humidity (RH) inside each ice rink is illustrated. By obtaining an additional information about the installations it can be tied to the graph that some ice rinks have RH-control, like ice rinks 1 and 2, where $\mathrm{RH}$ is around 70\% all season long.

For most ice rinks the $\mathrm{RH}$ value is decreasing until October after that levelling out, like in ice rink 3, 6, 7 and 8 . This is associated with the fact that the dehumidifier is running full capacity at the start of the season and as the load is decreasing with the ambient temperature and the associated humidity load the indoor RH decreases. Rink 5 stands out, having a completely different pattern than the others, which is due to the control strategy being based on humidity ratio, rather than $\mathrm{RH}$-value. Control strategies will be further discussed later in the paper.

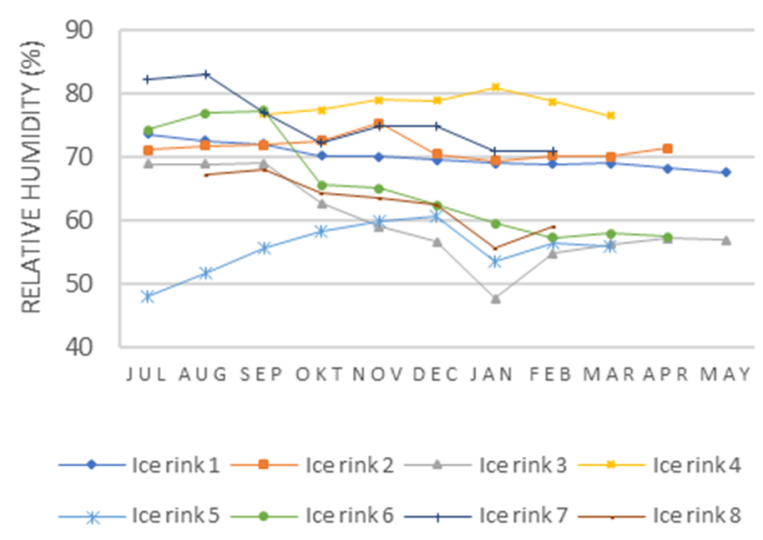

Fig. 6. Monthly average relative humidity.

\subsection{Humidity ratio}

With indoor temperature changing over the season but RH staying flat the absolute moisture content is going to vary. By using the temperature and relative humidity data from above, the water content per kilogram of wet air has been calculated according to the following equation:

$$
\omega=\frac{M_{w}}{M_{\text {air }}} \cdot \frac{P_{\text {sat }} \cdot R H}{P_{\text {atm }}-P_{\text {sat }} \cdot R H}
$$

In a typical ice rink to avoid excessive condensation on ice and surfaces, the recommended upper limit of humidity ratio is $4.3 \mathrm{~g} \mathrm{H} 2 \mathrm{O}$ per $\mathrm{kg}$ of air $\left(2^{\circ} \mathrm{C}\right.$ dewpoint $)$. While it is not required to perform an active dehumidification if the humidity ratio is below $3.7 \mathrm{~g} \mathrm{H} 2 \mathrm{O}$ per $\mathrm{kg}$ of air $\left(0^{\circ} \mathrm{C}\right.$ dewpoint $)$ because this would cause additional evaporation of water during ice maintenance (resurfacing).

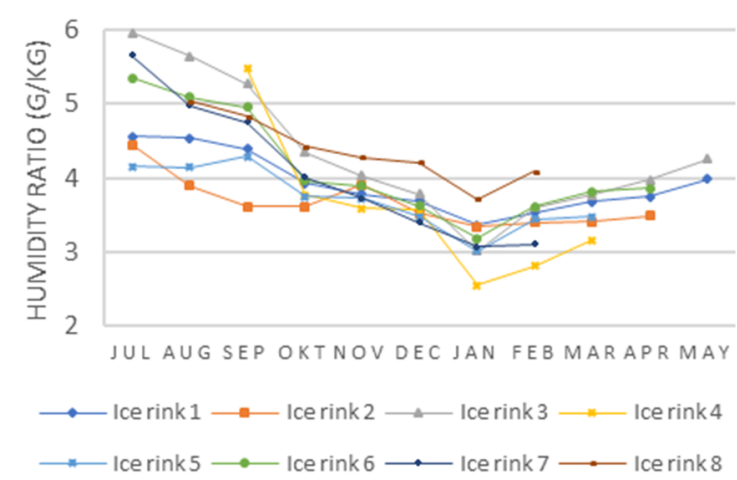

Fig. 7. Monthly average humidity ratio.

As can be observed in Fig. 7, in the beginning of the season most arenas have moisture levels well above the upper limit $4.3 \mathrm{~g} \mathrm{H}_{2} \mathrm{O} / \mathrm{kg}$ of air, that is explained by insufficient dehumidification capacity or poor controls.

Later in the season, indoor air in all arenas becomes drier following the trend of outdoor conditions, which gives a clear indication that indoor climate in real ice rink installations has a high dependency on the ambient climate.

\section{Moisture load}

Understanding where moisture load is generated is crucial for sizing dehumidification function appropriately, and this research addressed this matter with several methods, and for the most relevant moisture sources.

\subsection{Infiltration}

The temperature difference between indoor and outdoor climates and the height of the building can cause a significant air pressure differentials across the building envelope of an ice rink, so-called "stack effect". [6] Leaks through the building envelope allow warm and moist air to infiltrate continuously in the summer, e.g., conditions when temperature indoors $+8^{\circ} \mathrm{C}$ and outdoors $+25^{\circ} \mathrm{C}$

A practically convenient and accurate method to evaluate the air leakage is based on $\mathrm{CO}_{2}$ concentration in air. By doing measurements for a certain period of time, occupation periods can be easily tracked. In Fig. 8 data from one of the ice rinks can be seen. Concentration peak represents the end of occupancy after which air in the hall is exchanged gradually by air leakages and it happens during the night in this case. This decrease without other impacting factors can be used for calculations. The equation is as follows:

Where:

$$
A C H=-\frac{3600}{t} \cdot \ln \left(\frac{C(t)-C_{e x t}}{C_{0}-C_{e x t}}\right)
$$

$\mathrm{ACH}$ - Air change per hour $\left[\mathrm{h}^{-1}\right]$

$\mathrm{t}$ - Time interval [s]

$\mathrm{C}(\mathrm{t})-\mathrm{CO}_{2}$ concentration in the end of interval [ppm]

$\mathrm{C}_{0}-\mathrm{CO}_{2}$ concentration in the beginning of interval [ppm] $\mathrm{C}_{\mathrm{ext}}$ - outside $\mathrm{CO}_{2}$ concentration during the interval [ppm] 


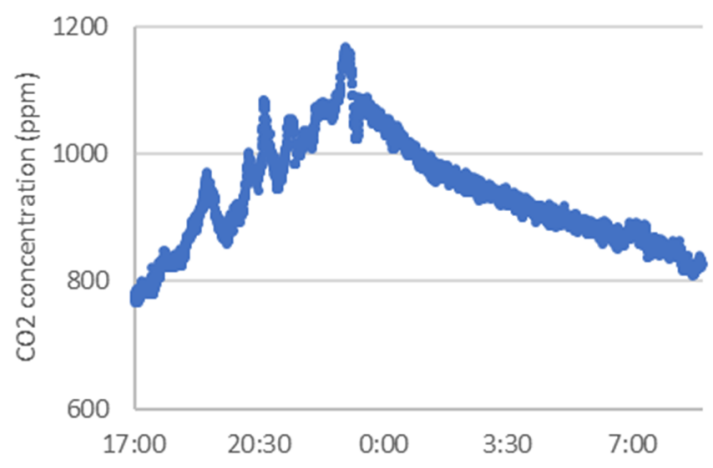

Fig. 8. Example of a $\mathrm{CO}_{2}$ concentration measurement.

The estimated $\mathrm{ACH}$ for this ice rink is $0.13 \mathrm{~h}-1$. Assuming arena volume $23000 \mathrm{~m}^{3}$, the fresh air brought in by air leakage is $3000 \mathrm{~m}^{3} / \mathrm{h}$. [3]

A number of other reference measurements suggest typical ACH in the range between 0.05 to $0.15 \mathrm{~h}-1$.

\subsection{Internal sources}

Ice rinks are public buildings and occasionally there are events which attract a large number of spectators who are watching sportsmen in action. Reasoning about the moisture load from people presence should be done, to understand its potential magnitude in the moisture balance.

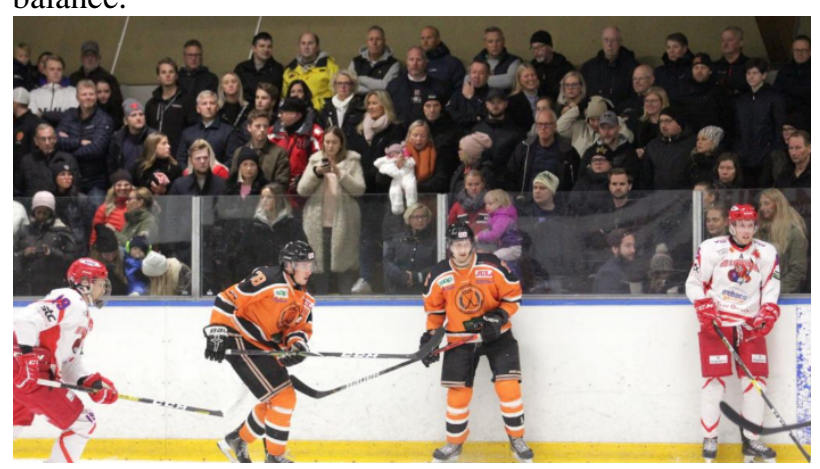

Fig. 9. Spectators in a normal size ice rink.

Water vapor from a human body is released by sweating and breathing. Large part of the sweat is absorbed by clothing, and in ice rinks either the spectators and players normally have clothing that covers most of the body. Due to this reason sweating as a moisture source may be neglected. Breathing on the other hand releases water vapor directly to the air. A method to evaluate the moisture generated by the respiratory process is suggested in the Chapter 9.4 of ASHRAE Fundamentals handbook, where the activity has the major significance. Using an example of a typical size ice rink in Sweden, it can be assumed that the number of spectators is 500, watching an ice hockey game, with around 40 players in having an activity with high intensity. The total resulting moisture release by spectators is $3.9 \mathrm{~kg}$ per hour and by players 1.5 $\mathrm{kg}$ per hour, and in total $5.4 \mathrm{~kg} \mathrm{H}_{2} \mathrm{O}$ per hour.

The impact is considerable, however it is important to understand whether the load would potentially cause moisture related problems. The nature of such source is relatively short-term, because events with large amount of people are not as frequent and not happening one after another. This means it might be possible to encounter peaks of the indoor humidity ratio during the day for a couple of hours. Once the rink is empty, the air will start to dry out to the level which is set by all the other moisture sources.

During conditions when ambient air is more wet than the indoor it is not possible to track the internally generated moisture load, because the magnitude of it is much lower than infiltration caused moisture influx. A practical way of analyzing the internal moisture load is to look into a shorter period like in where two dry days are chosen for this particular matter. At these conditions the only considerable source apparently is the activity of people, as can be seen on $12^{\text {th }}$ of January between 18 and 21 the indoor humidity ratio rises slightly, although the ambient air is drier. The logical reason for this might be an event in the ice rink, like an ice hockey game with many spectators. This rise in the 3 hour span was used and the estimated results show a moisture generation of around $3.1 \mathrm{~kg}$ of water per hour, which is close to what was calculated using the theoretical assumptions.

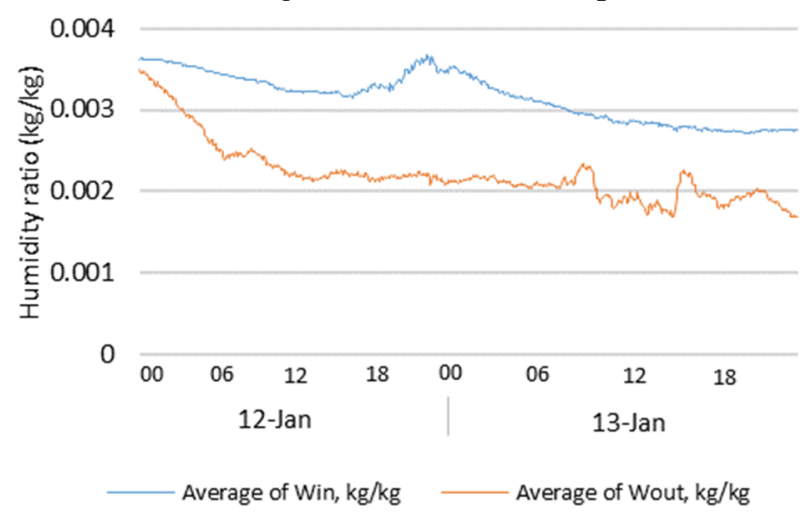

Fig. 10. Humidity ratio indoors and outdoors for two day period.

Although this is not a very accurate assumption, because the exfiltration removes moisture during this period. A more credible results would be achieved if a period with similar air humidity ratio on both sides of the envelope would be chosen, however occasional peaks were not observed during such conditions.

Although often mentioned as a potential internal humidity load, the resurfacing flood water turns out to be a negligible internal source. This is due to the fact that the water, regardless of temperature, is cooled down to the freezing point instantly. [7] During the freezing process it may only evaporate if the dewpoint in the arena room is below $0^{\circ} \mathrm{C}$. This is one of the reasons that the control humidity level is suggested to always be above $0^{\circ} \mathrm{C}$.

\subsection{Diffusion}

Diffusion through the building envelope is another mechanism of moisture transport. The water vapor in air moves from higher water vapor content towards lower by the partial water vapor pressure gradients. This happens 
in parallel to water vapor migration with air leakages and is considered as a separate process. Here the pores and cracks in the building material or gaps between the joints give the opportunity for vapor to migrate.

As compared to the air leakages, diffusion through the building envelope in ice rinks is a much slower process, which is why the moisture displacement magnitude is lower. Using the results from a study, where different wall types for ice rinks were compared, the impact of the diffusion through wall on the indoor humidity ratio is estimated to be insignificant. For air conditions in august, when there is the highest water vapor difference, the diffusion through the wall is evaluated to be a moisture source with a rate of $135 \mathrm{~g}$ of water per hour. This result gives a strong argument that it is not essential to consider water vapor diffusion through a wall in the moisture balance. [8].

More severe effect might be on the building structures on the other hand. If unproperly designed or built at the given climate, the vapor may condense with concentration in particular spots or layers. By the time it will deteriorate the thermal insulation properties (increase heat conductivity), create favorable conditions for mold growth or in the worst-case lead to structural failures. To avoid condensation within the wall structure, first the direction of diffusion process should be considered, subsequently the layers in the wall can be chosen in such a way that material can naturally ventilate. Analysis can be made for a whole year performance, taking into account the weather data and indoor air conditions. As a result mold growth potential is assessed. Even if the condensation happens at certain conditions, it might not be for a long period and further changes in the weather along a year might be favorable for the wall to dry out.

Three representative locations were analysed from the humidity ratio perspective. The locations were chosen in such a way that the ambient air conditions represent the northern part (Kiruna), mid part (Stockholm) and southern part (Malmö) of Sweden. An evident trend was observed, monthly average humidity ratio range for a normal year is around 1.0 to $6.3,2.5$ to $9,3.5$ to $9.6 \mathrm{~g} \mathrm{H}_{2} \mathrm{O}$ per kg of dry air in the north, mid and south respectively. This difference implies that the direction of the diffusion depending on the location will affect the wall design.

\subsection{Total}

To summarize the analysis that is done with respect to loads Fig. 11 is shown. This is to put the contributions in relation to each other, which comes from the fact that in literature and in practice there are very different assumptions about the magnitude of the different parts. The source of the variations comes from very different assumptions, especially regarding air leaks and internal loads. This study has attempted in a nuanced way to analyze the loads theoretically and then to put them in relation to the field measurements performed to verify the calculations.

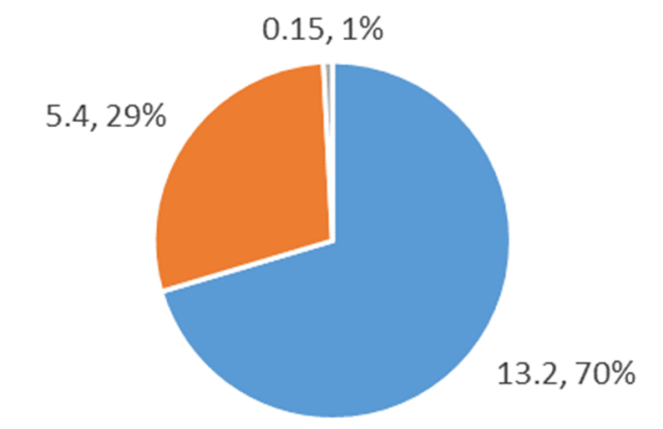

" Air leakage घ Internal sources घ Diffusion

Fig. 11. Moisture loads at maximum internal loads and otherwise nominal conditions an ice rink.

In this case, it has been assumed that the indoor/outdoor temperature is $7 / 15^{\circ} \mathrm{C}$, the air leakage is $13 \%$ which contributes to the external load and that 500 spectators and 40 players are responsible for the internal loads. As previously noted, diffusion through walls and ceilings accounts for a vanishingly small proportion, but it is included to put it into perspective. As can be noted, the total loads amount to just under $20 \mathrm{~kg} /$ hour and then the internal loads are at their highest level. During most of the ice rink service life, the internal loads are basically 0 , which means that the load is the air leakage, which in this case would mean about $13 \mathrm{~kg} /$ hour.

If, for the same plant, the worst case was assumed when there is the highest possible humidity in the outdoor air, i.e., $12 \mathrm{~g} \mathrm{H} 2 \mathrm{O}$ per $\mathrm{kg}$ of air, then the contribution of the air leakage part would rise to close to $30 \mathrm{~kg} / \mathrm{hour}$. The design internal loads are the same, ie about $5 \mathrm{~kg} / \mathrm{hour}$, which gives a total contribution of about $35 \mathrm{~kg} / \mathrm{hour}$. Now these levels of load are short-lived in such a plant, which is why it is normally not necessary to design for these levels.

\section{Moisture removal}

The humidity mass balance involves several moisture "sinks" and ice rinks require controlled moisture removal to avoid problems associated with it.

\subsection{Ice surface}

When the humid air in the rink space "meets" with the cold ice surface it condenses and subsequently frost is formed on the ice. In this way a part of vapor in air inside the rink space change its phase to ice and mass of it is transferred. For this to happen ice temperature must be lower than the dew point of the air, which is the case most of the time normally, especially during warm part of the season, when condensation rates are the highest.

This has a cost nevertheless, because the condensation adds a heat load to the refrigeration system, as well the quality of ice deteriorates due to excessive condensation rates. Since it is practically not beneficial to decrease the dew point of air below $0^{\circ} \mathrm{C}$, condensation is inevitable (as the ice temperature is below $0^{\circ} \mathrm{C}$ ). Therefore, the goal is 
not to eliminate it, but to take care that the condensation rate does not add too high cooling load or has a negative impact to the ice quality.

To estimate the amount of water that is transferred from the air to the ice surface, several calculation methods are applicable. As the physical process behind the diffusion of water vapor involves heat and mass transfer, it is key when aiming to predict the rate of the transported mass of water. Fig. 12 shows results of the study, where two different analogies were used to estimate water that is condensed to the ice, with a typical area of $1800 \mathrm{~m}^{2}$. [9] Different air velocities above the ice surface were assumed, higher velocity leads to a higher heat and mass flux, at the same time lower ice temperatures intensify the process.

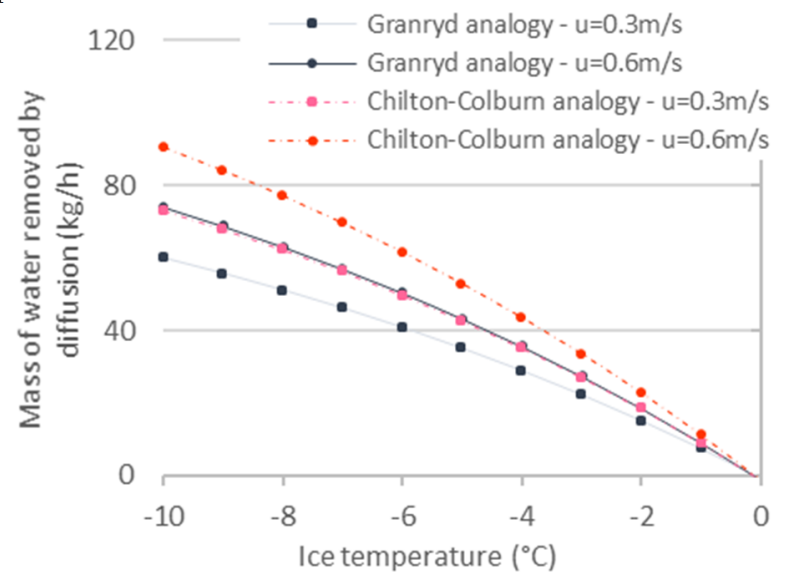

Fig. 12. Mass of water transferred from air to ice. [9]

There has been found a high sensitivity to the ice temperature, as an example if values at $-3^{\circ} \mathrm{C}$ and $-6^{\circ} \mathrm{C}$ ice temperature are compared, using the velocity of $0.5 \mathrm{~m} / \mathrm{s}$ and Granryd analogy, the difference in magnitude is almost twice.

To estimate the amount of water that diffuses to the ice in a certain ice rink, the design indoor conditions and ice temperature should be known. The given figures are based on an assumption that the air above the ice slab has a dew point of around $-0.1^{\circ} \mathrm{C}$. The more humid the air the more mass of water will be transferred from the air to the ice. The latent and sensible heat flux that is added to the refrigeration load due to diffusion, means that the intentional dehumidification by the ice slab is not for free, it impacts the refrigeration system size and the energy use, not to mention the ice quality worsening.

\subsection{Dehumidification}

Available set of data - temperature, $\mathrm{RH}$ indoor and outdoor, electrical and heating capacity of the sorption dehumidifier for the whole season allowed to do a performance analysis. The datasheet of the particular dehumidifier model gives an information of the expected water removal capacity at certain process air property state, which can be seen in Fig. 13. Interpolations between the corresponding lines are done in order to get a better precision of the expected capacity - at each 0.1 degree Celsius and $1 \%$ relative humidity step.

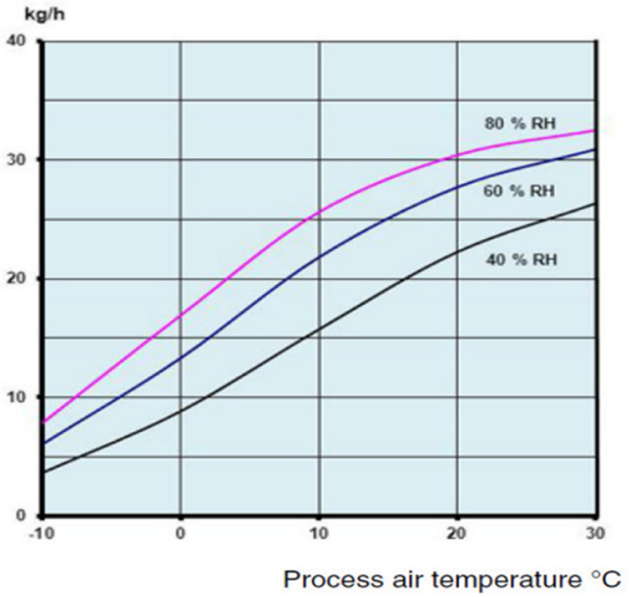

Fig. 13. Dehumidification performance of the analysed unit.

However, the given datasheet above assumes full electrical/heating power, which is not always the case. Thus, proportion of the actual power meter measurement and rated power corresponds to the actual water removal rate. Note that in the given performance curve, the water removal capacity will decrease if the process air is drier, even if the same heating capacity is supplied to the sorption wheel.

In Fig. 14 water removal capacity for the whole season in two studied ice rinks is shown, on a daily average basis. A good indicator for the load, is the outdoor temperature, hence it is used as a reference. In the ice rink 1 the dehumidifier is set to indoor dew point of around $0.4^{\circ} \mathrm{C}$ or humidity ratio of $3.9 \mathrm{~g} / \mathrm{kg}$, thus no moisture removal happens during low ambient temperature. The capacity reaches almost $20 \mathrm{~kg}$ of water removed per hour. With this capacity the setpoint at the warm and wet part of the season is not fully met, and this happens at certain days between the end of July until the end of September. The highest experienced indoor air dewpoint is around $4.5^{\circ} \mathrm{C}$ or $5.2 \mathrm{~g} / \mathrm{kg}$ humidity ratio.

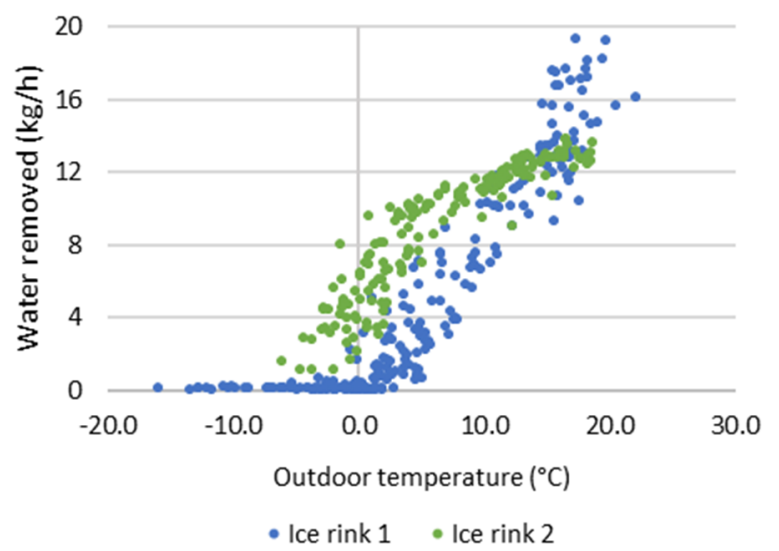

Fig. 14. Dehumidification capacity of units in studied ice rinks.

\subsection{Total moisture removal}

The two main moisture sinks are the ice surface and the dehumidifier. The ice surface is a bigger "dehumidifier" 
than one might think. The laws of physic provide that the capacity can be several 10's of kg's per hour - depending on the moisture content of the air and the temperature of the ice. The greater the difference in saturation state between the ice surface, i.e., its temperature and the moisture content of the air - the greater the mass transport from the air to the ice surface. The calculations made are quite sensitive because they depend on the conditions that prevail in terms of air velocities, air temperature, moisture content, etc. These quantities, in addition to the air velocity, which is not measured but only assumed, have been measured in the "bulk volume" of the ice rink, i.e., at a great distance from the ice surface. Consequently, the conditions can be quite different, which of course strongly affects the calculation. This area is interesting to continue investigating in the future as it potentially accounts for a relatively large proportion of moisture transport.

Of course, the second and perhaps most interesting part of the moisture management is the dehumidifier, and it was found that capacities of the order of $20 \mathrm{~kg} / \mathrm{hour}$ are required for operation during the hottest part of the season. The point loads in a training hall can be up to 30$35 \mathrm{~kg} /$ hour at the highest possible moisture content in the outdoor air in combination with the maximum number of spectators. It is now relatively unlikely that these two maximums coincide, which is why this study estimates that sizing the dehumidifier capacities up to about 20 $\mathrm{kg} /$ hour is usually sufficient.

\section{Moisture control in ice rinks}

Goal of a dehumidification system is to have an indoor environment that is maintained at acceptable conditions. For it to happen the dehumidification function must be control accordingly.

\subsection{Energy signature}

The building envelope separates climate zones with different air properties from each other, but these are never ideally isolated. The main driving force of air movement is the temperature difference. A handy and accountable parameter that is used in this paper is the humidity ratio which also happens to be proportional to the temperature of air, meaning that the direction of moisture flow is towards the lowest humidity ratio. This can be called the humidity ratio difference and is calculated as follows:

$$
\Delta W=W_{\text {out }}-W_{\text {in }}
$$

It is worth to mention here also that relative humidity cannot be used for this purpose. In residential buildings, offices or other typical indoor climate buildings, the moisture flow direction is usually from the inside to the outside, while in ice rinks for most of the season the flow is from the more humid outdoor air to the less humid indoor air.

Available data from ice rinks is used to calculate their respective humidity ratio differences, which in Fig. 15 are put into relation to the dehumidification energy usage of each ice rink. The linear trendlines show a similar pattern, where a higher humidity ratio difference leads to an increase in the need for dehumidification. Again, this suggests that outdoor air adds a significant moisture load. [2]

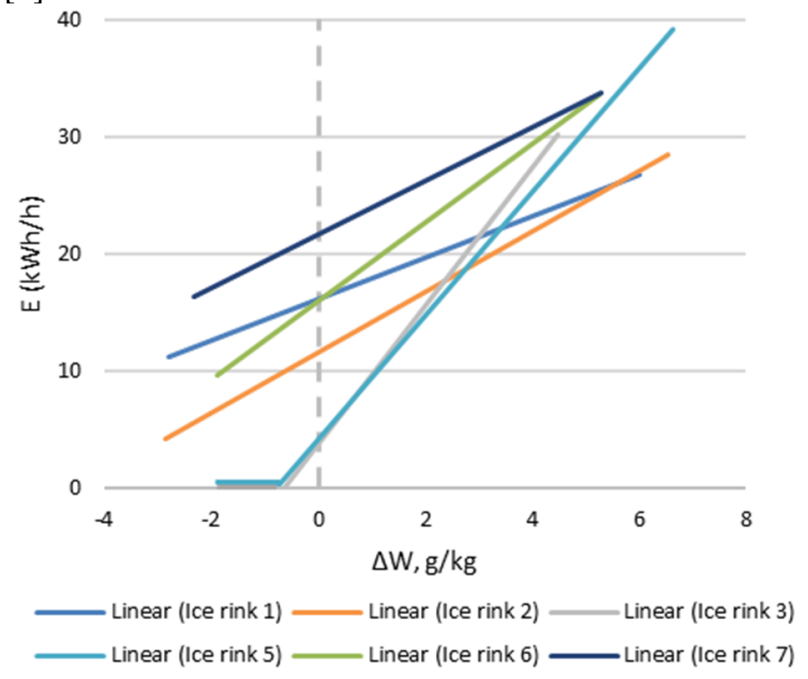

Fig. 15. Dehumidification energy signatures.

Theoretically, when the humidity ratio difference is zero the outdoor air has a humidity ratio that is acceptable for the indoor environment since there is no major moisture exchange between the indoor and outdoor air. Because there is no influence from the ambient air at a zero-infiltration rate, the moisture to be removed from the indoor air should only emerge from internal sources like spectators or the resurfacing process. If the outdoor air becomes drier than indoor air the difference becomes negative and the moisture exchange between indoor and outdoor air changes direction, consequently dehumidifying the indoor air partly through a natural process. In Fig. 15 it can be observed that in ice rinks 1, 2, 6 and 7 the energy usage while there is a negative infiltration rate is still between 5 and $22 \mathrm{kWh} / \mathrm{h}$, which is a significant load suggesting that it is either the internal load and/or suboptimal control strategy that still keeps the dehumidifier going. Ice rinks 3 and 5 show a much lower dehumidification activity in the negative range and after a certain point the dehumidifier is not operating at all. This implies that internally generated moisture is removed through air leaking out, which is a natural process and does not require any dehumidifier assistance. In ice rink 5 the dehumidifier is controlled according to humidity ratio, avoiding the risk of "over drying" which significantly reduces the electricity bill.

\subsection{Improved control strategy}

Correct control of humidity level is important to achieve good ice quality and healthy indoor climate in the most energy efficient manner. The field measurements suggest a 30+ percent energy reduction when changing the control strategy from the typical relative humidity to dew point. The dehumidifier should be controlled to maintain a dew point between $0^{\circ} \mathrm{C}$ and ca $2^{\circ} \mathrm{C}$ in typical ice rinks, where indoor temperatures move between $5-10^{\circ} \mathrm{C}$. If it's lower than $0^{\circ} \mathrm{C}$ it intensifies the moisture loads and if it is higher 
than $2^{\circ} \mathrm{C}$ there is an increased risk of problems related to condensation. Fig. 16 shows over time how energy is saved by applying a control strategy based on dew point instead of the traditional relative humidity, where the latter especially tends to "over dry" the arena room when there actually is no dehumidification demand.

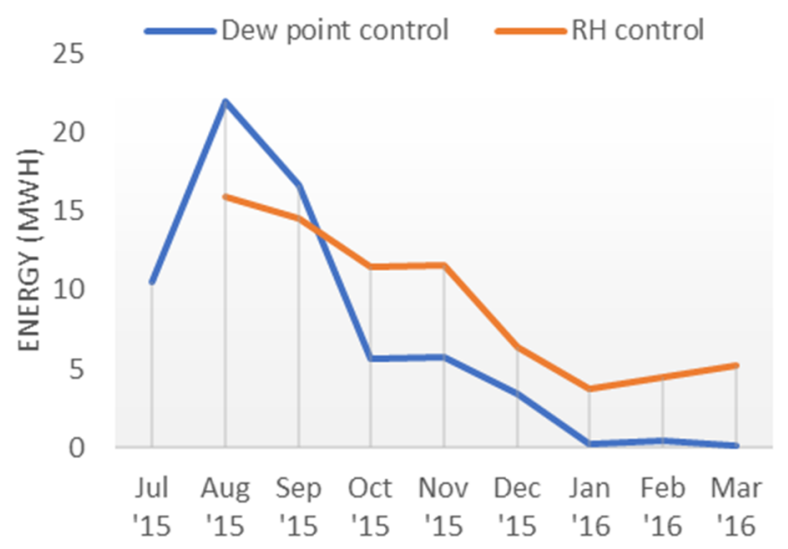

Fig. 16. Comparison of energy use between control strategies based on relative humidity and dewpoint/humidity ratio in two ice rinks.

Once again, the pattern is verified that the dehumidifier that is controlled to humidity ratioor dew point will stop operating when the demand decreases whereas the RH controlled often continues to operate. The reason being the lower air temperature in the ice rinks at the colder period which still generates a "high" RH although the dew point (and moisture content) is low.

Based on the results and discussion above it seems that the best option is to control the humidity to the humidity ratio or the dew point. It is much a more precise control, especially when the indoor temperature changes along the season. Even if the relative humidity control is done according to recommended values at the temperature range, it requires continuous manual change in settings, which is not a modern approach and is not as precise.

\section{Summary}

This paper addresses the importance of dehumidification function in indoor ice rinks with controlled environment. The project has had access to numerous measurements carried out in ice rinks, and "actual operating conditions" in facilities of this type are presented. The bulk of data shows that expected temperature is within the range $+5^{\circ} \mathrm{C}$ to $+10^{\circ} \mathrm{C}$, humidity ratio can vary between 2.5 to 6.0 $\mathrm{gH}_{2} \mathrm{O} / \mathrm{kg}$ of air.:

The moisture sources in an ice rink can be divided into two groups: External and Internal. Air leakage turns out to be the biggest moisture source by far, which is not only in theory but also supported by the field measurement data trends.

The moisture removal happens through two main processes. Firstly, via water vapor condensation on ice, which needs to be limited but is unavoidable. Secondly, by active dehumidification which absorbs the excess moisture and is the primary tool for controlling the indoor environment.

For appropriate moisture handling approach in ice rinks, the humidity levels should be discussed by using absolute terms such as "dewpoint" or "humidity ratio". This report shows that the dewpoint in an ice rink should be maintained between $0^{\circ} \mathrm{C}$ and ca $2^{\circ} \mathrm{C}$ in order to secure a sustainable indoor climate, good ice quality and best economy of operation.

A case study shows that by changing controls from $\mathrm{RH}$ to absolute humidity or dewpoint, about $30 \%$ of the energy for the dehumidifier can be saved.

The authors would like to acknowledge the NERIS project initiated and managed by the department of Civil Engineering at the KTH, Royal Institute of Technology.

\section{References}

1. J. Rogstam, J. Pomerancevs, S. Bolteau, and C. Grönqvist, "NERIS del 1: Fuktproblematiken i ishallar - en introduktion," Stockholm, 2017.

2. J. Rogstam, J. Pomerancevs, S. Bolteau, and C. Grönqvist, "NERIS del 2: Metoder och energianvändning för avfuktning i ishallar," Stockholm, 2017.

3. J. Rogstam, J. Pomerancevs, S. Bolteau, and C. Grönqvist, "NERIS del 3: Fukttransport i ishallar - mekanismer och fysik," Stockholm, 2018.

4. J. Rogstam, C. Beaini, and J. Hjert, "Stoppsladd: Energianvändning i svenska ishallar," Stockholm, 2014.

5. ORFA, "Understanding the Impact of Humidity in an Ice Rink," 2014.

6. J. T. Lin and Y. K. Chuah, "Prediction of infiltration rate and the effect on energy use for ice rinks in hot and humid climates," Build. Environ., vol. 45, no. 1, pp. 189-196, 2010.

7. R. Kaya, "Energy usage in ice rink resurfacing," Royal Institute of Technology, Stockholm, 2017.

8. S. Yousif and A. Douglah, "Hur skall en ishallsvägg byggas?," KTH, Byggteknik och design, Stockholm, 2017.

9. J. Rogstam and W. Mazotti, "Ice rink dehumidification systems energy usage and saving measures," in 11th IEA Heat Pump Conference 2014, 2014. 